\title{
1 Kinetics and Fidelity of Psychrophilic DNA 2 Polymerases
}

3 Yuan Xue ${ }^{1}$, Ido Braslavsky², Stephen R. Quake ${ }^{1,3,4 *}$

4 1. Department of Bioengineering, Stanford University, Stanford, CA, USA

5 2. The Robert H. Smith Faculty of Agriculture, Food and Environment, Institute of

6 Biochemistry, Food Science, and Nutrition, The Hebrew University of Jerusalem, Rehovot

7 7610001, Israel

8 3. Department of Applied Physics, Stanford University, Stanford, CA, USA.

9 4. Chan Zuckerberg Biohub, Mission Bay, CA, USA.

10 KEYWORDS: Polymerase fidelity. Psychrophilic DNA polymerase. Temperature effect on 11 enzymes. Polymerase error rate.

13 Abstract: The discovery of extremophiles has enabled development of groundbreaking 14 biotechnology. While most of the extremophile research is focused on thermophiles, organisms 15 that adapt to living in cold temperature, known as psychrophiles, remain under-studied. We 16 expressed and purified DNA polymerases PIPI and PIPB from Psychromonas ingrahamii, a 17 psychrophile that can grow below water's freezing temperature. We demonstrate that they have 18 in vitro DNA replication activity at temperatures as low as $-19^{\circ} \mathrm{C}$. To our knowledge, this is the 19 coolest DNA polymerization reaction ever carried out in a laboratory. In exploring the behavior of a variety of polymerases as a function of temperature, we found that reaction temperature

21 substantially increases substitution and deletion error rates of both psychrophilic and mesophilic DNA polymerases. Motif analysis further reveals that the substitution error profiles cluster

23 according to phylogenetic similarity of polymerases. Our results provide a useful reference for 

available under aCC-BY-ND 4.0 International license.

24 how reaction temperature, a crucial parameter of biochemistry, can affect the fidelity of DNA 25 polymerases adapted to a wide range of environment. 


\section{Introduction:}

Life in cold environment is confronted with the thermodynamic obstacle of maintaining

28 sufficient enzymatic activity; however, the abundance of various life-forms found in near or below freezing temperature suggests that biology has evolved ways to overcome such challenge. Contrary to what one would expect from naïve application of Arrhenius equation, life-forms that adapted to living in cold environment do not grow exponentially slower in the cold than their mesophilic cousins at room temperature ${ }^{1,2}$. This suggests that efficiency of psychrophilic enzymes are evolutionarily adapted to sustain relevant metabolism in low temperature ${ }^{3-5}$. Low temperature adaptation of enzyme is thought to increase the catalytic rate by increasing local flexibility of active site, thus lowering activation energy barrier ${ }^{6-8}$. This can be contrasted with high temperature adaptation which often confers global structural robustness to an enzyme by increasing intra-molecular interactions that maintain functional tertiary shape. Studies based on directed evolution have shown that structural stability and enzymatic efficiency can be optimized simultaneously and are thought to be mutually compatible properties ${ }^{9,10}$. Combining the observations helps to explain the general biochemical trend of cold-adapted enzymes (summarized in Figure 1a): an increase in enzyme's catalytic activity is often associated with a

42 reduced binding affinity and a broader substrate specificity ${ }^{11,12}$. However, a direct test of these

43 ideas on orthologous enzymes from organisms adapted to low, medium, and high temperatures has not yet been performed.

As DNA polymerase is a central component of cellular replication and biotechnological 46 platforms ${ }^{13}$, understanding how reaction temperature can affect fidelity is of vital interest. Polymerase error rate is tightly controlled to ensure the duplication of genetic material which can encode functional descendants. Replication error from DNA polymerase is a source of genetic variations and underlies the cause of many inheritable diseases ${ }^{14-17}$. Polymerase errors play a crucial role in biotechnology applications such as polymerase chain reaction (PCR) and multiple-

51 displacement amplification (MDA) ${ }^{18-20}$. Polymerase errors can introduce base mismatches and

52 indels at an exponential rate, significantly impairing downstream interpretation. In high- 
53 throughput sequencing, replication errors of polymerase can reduce accuracy and precision of

54 base calling ${ }^{21-23}$. To test the effect of temperature on polymerase fidelity, we characterized error

55 rate of a variety of DNA polymerases as a function of temperature. Furthermore, we explored

56 how temperature adaptation affects polymerase fidelity at different reaction temperatures by

57 characterizing the error profiles of DNA polymerases of psychrophilic, mesophilic, and

58 thermophilic origins. Combining unique molecular indices (UMIs) and high-throughput sequencing, we carried out a multiplexed measurement of substitution, insertion, and deletion error rate at the single-molecule level for seven different DNA polymerases, some of which are commonly used in molecular cloning and sequencing applications. Our data provide evidence that the error rate of cold-adapted DNA polymerases are more sensitized to fluctuations in reaction temperature than thermal-adapted ones. Our study reveals how temperature adaptation affects psychrophilic DNA polymerase kinetics and fidelity which may enable biotechnology development.

\section{Materials and Methods:} found on Joint Genome Institute, Integrated Microbial Genomes \& Microbiomes (IMG/G) portal (IMG id: 639633052). The sequences were codon optimized for E. coli expression. PIPI gene fragment (1845 bp) was synthesized and cloned into pD454 T7 expression vector (Ampicillin resistance) by ATUM (formerly DNA 2.0) to generate a maltose-binding protein (MBP) fusion gene containing a single HRV 3C cleavage site. PIPB was synthesized by Integrated DNA Technologies (iDT) as a single DNA fragment (2430 bp). The fragment was amplified in PCR with primers containing 5'-NdeI and 3'-SalI sites, and the resulting product was digested and ligated into linearized pMAL-c5x vector (New England Biolabs). All cloning products were first subcloned in NEB-5 $\alpha$ strains and then purified using ZymoPURE plasmid miniprep kits (Zymo Research). The sequences of the expression constructs were all verified with Sanger sequencing by Sequetech. Plasmid maps for the constructs used in this study are provided (Supplemental 
Polymerase Purification. Several expression and purification conditions had been attempted to optimize yield and purity of active polymerase products. We first attempted to express a media. Isopropyl $\beta$-D-1-thiogalactopyranoside (IPTG) induction of protein expression was carried out at $16^{\circ} \mathrm{C}$ between 12 - 16 hours. Harvested cells were lysed with either 5 freeze-thaw cycles or a sonicator. We screened a variety of lysis buffer and found that most of the protein remained insoluble. We suspect that GST-tag does not promote protein solubility based on previous reports $^{24}$. In our second approach, we generated MBP-PIPI (112.4 kDa) and MBP-PIPB $(134.8 \mathrm{kDa}$ ) fusion genes on a pMAL-c5x vector expressed in Arctic Express DE3 (Agilent Technologies), a bacterial expression cell line that overexpresses psychrophilic chaperones. Instead of LB, we grew the bacteria in a defined media M9ZB (Supplemental text 2) at $37^{\circ} \mathrm{C}$ until OD600 of 2.5 and induced expression with $1 \mathrm{M} \mathrm{IPTG}$ at $10^{\circ} \mathrm{C}$ or $16^{\circ} \mathrm{C}$ for $20-24$ hours. Cells were harvested in lysis buffer (20 mM Tris- $\mathrm{HCl}$ pH 7.50, 10\% glycerol, $50 \mathrm{mM} \mathrm{NaCl}, 10 \mathrm{mM} 2-$ Mercaptoethanol) with the additions of $400 \mathrm{U}$ of DNase I and $1 \mathrm{X}$ protease inhibitor cocktail (No EDTA; ThermoFisher). Cells were lysed in French press homogenizer by passing through at 500 psi once, and at 10000 psi for three times. Clarified cell lysate was mixed with amylose resin at $4^{\circ} \mathrm{C}$ for three hours. Resin was washed with 20 column volumes of chaperone removal buffer (20 $\mathrm{mM}$ Tris- $\mathrm{HCl} \mathrm{pH}$ 7.50, $10 \%$ glycerol, $50 \mathrm{mM} \mathrm{NaCl}, 10 \mathrm{mM}$ 2-Mercaptoethanol, $50 \mathrm{mM} \mathrm{KCl,} 5$ mM ATP) and washed with 10 column volumes of lysis buffer (with no addition of DNase I or protease inhibitor). Bound proteins were eluted by incubating at $4^{\circ} \mathrm{C}$ for 3 hours with $10 \mathrm{mM}$ of maltose. MBP-PIPI was subjected to $\mathrm{HRV}-3 \mathrm{C}$ cleavage at $4^{\circ} \mathrm{C}$ overnight. We did not cleave MBP-PIPB as it was found to induce precipitation of the protein. Both proteins were further purified in HiLoad 16/60 Superdex 200 preparatory grade size exclusion column (GE Healthcare) to separate fractions of polymerase proteins from contaminating proteins. Purified proteins were eluted in lysis buffer, concentrated in Amicon Ultra protein filters, and then stored in $-80^{\circ} \mathrm{C}$ until experiments.

107 Protein quantification. Protein concentration was quantified by loading proteins on denaturing SDS-PAGE gel and stained with SYPRO Red following the manufacturer's 
110 established by separately staining a titration series of known amount of MBP-paramyosin-Sal. A

111 secondary quantification measurement with Bioanalyzer Protein Analysis Kits (Agilent)

112 provided similar concentration values as SYPRO Red assay (data not shown).

113 Polymerase Activity Assay. Polymerase activity from $5^{\circ} \mathrm{C}$ to $50^{\circ} \mathrm{C}$ was measured with

114 EvaEZTM Fluorometric Polymerase Activity Assay Kit (Biotium) according to the provided

115 protocol. Briefly, assay mix and polymerase of known concentrations were equilibrated to the

116 reaction temperature separately for 5 minutes before mixing. Fluorescence signals of Eva

117 dsDNA binding dye and ROX reference dye were measured in Bio-rad 96 well qPCR machine

118 for 1 hour at constant reaction temperature with 30 seconds interval. Titrations of the polymerase

119 were performed at $20^{\circ} \mathrm{C}$ to ensure linear response of measured activity at the given polymerase

120 concentration. A positive control sample with saturating amount of Klenow Exo- polymerase

121 was included to ensure that maximal fluorescence signals remained constant over the course of

122 measurement at each reaction temperature. The initial slope of the fluorescence gain for each

123 polymerase is used to estimate the steady-state speed of replication. The slopes are then

124 normalized to the maximal slope measured across all temperature range for each corresponding

125 polymerase.

126 Gel Extension Assay. For measurement of subzero polymerase activity, we prepared $9.5 \mu \mathrm{L}$ of

127 primed extension mix containing a final concentration in $10 \mu \mathrm{L}$ volume of $10 \mathrm{nM}$ primed

128 template with 5'-ATTOTM 633 fluorescent label (iDT) (Supplemental text 1), $50 \mu \mathrm{M}$ dNTP, 10

$129 \mathrm{mM}$ MOPS pH 8.50, 30\% glycerol, $1.5 \mathrm{mM} \mathrm{MgCl} 2,0.1 \mathrm{mg} / \mathrm{mL}$ BSA, $50 \mathrm{mM} \mathrm{KCl}$. Reaction

130 master mix and polymerase were separately equilibrated to $-19^{\circ} \mathrm{C}$ on a TropiCoolerTM (Boekel

131 Scientific) for 30 minutes, then they were rapidly mixed with pre-chilled pipette tips. One

132 microliter aliquot of the reaction was quenched in $9 \mu \mathrm{L}$ of $90 \%$ formamide with $50 \mathrm{mM}$ EDTA

$133 \mathrm{pH} 8.0$ and heat denatured at $95^{\circ} \mathrm{C}$ for 5 minutes before cooling on ice. For exonuclease assay, a

134 similar reaction was prepared but without the addition of dNTP. After thermal equilibration, the

135 polymerase was mixed with the reaction master mix and incubated on the thermal cooler. One

136 microliter of the quenched mixture was resolved on $15 \%$ polyacrylamide TBE-Urea precast gels

137 (Bio-rad) at 195 constant voltage for 50 minutes. Gels were imaged on Typhoon 9410 imager

138 (GE). 
Molecular Barcoding and Library Preparation. We purified homogeneous $\left(<10^{-9}\right.$ single nucleotide polymorphism per base) pUC19 plasmid template from a single clone of NEB-5 $\alpha$

141 (New England Biolabs) transformed with pUC19 grown in LB supplemented with ampicillin

142 antibiotic. About $1 \mu \mathrm{g}$ of purified pUC19 was co-digested with 10 units of SapI and NdeI at $37^{\circ} \mathrm{C}$

143 for 24 minutes. Digested pUC19 template fragment was purified twice with $0.35 \mathrm{X}(\mathrm{V}: \mathrm{V})$ of

144 Ampure XP beads. Concentration and purity of the co-digested pUC19 template was determined

145 on Bioanalyzer using high-sensitivity dsDNA quantification kit. Applying UMI barcoding

146 strategy to measure polymerase errors on single-molecule level has been reported previously by

147 the Xie group ${ }^{25}$. We adapted their strategy to measure polymerase replication at different reaction

148 temperatures. All reactions were conducted in a buffer made up of $10 \mathrm{mM}$ MOPS pH 8.50, 30\%

149 glycerol, $1.5 \mathrm{mM} \mathrm{MgCl} 2,0.1 \mathrm{mg} / \mathrm{mL}$ BSA, $50 \mathrm{mM} \mathrm{KCl}$ unless otherwise stated. We used MOPS

150 buffer instead of Tris-based buffer as it has a much smaller $\Delta \mathrm{pKa} / \Delta \mathrm{T}$ scaling which minimizes

151 changes in buffer acidity at different temperatures. We increased the UMI length to 15

152 nucleotides on both ends, effectively increasing the combinatorial space to $4^{30}$ which minimizes

153 the barcode collision rate between UMIs (Supplemental text 1). After annealing UMI index

154 primer to pUC19 template (100:1 molar ratio), we pre-incubated the reaction mixture in 96 well

155 plate at the desired reaction temperature for 2 minutes prior to the addition of polymerase

156 (volume of reaction mixture to volume of polymerase is 19:1). Reaction was quenched with 50

157 mM EDTA after giving sufficient time to complete the reaction. Reaction time for each

158 polymerase and condition was determined using fluorometric activity assays and qPCR

159 measurement. We then purified the reaction mixture with Ampure beads and synthesized the

160 complementary strand using the reverse UMI primer with Q5 DNA polymerase in its native

161 reaction buffer (NEB) by incubating at $72^{\circ} \mathrm{C}$ for 10 minutes which is followed by EDTA

162 quenching. We performed a second round of DNA purification and quantified molecular

163 concentration of the resulting products using qPCR. A total input of 20000 barcoded molecules

164 from each reaction was amplified in two rounds of 13 PCR cycles, with Ampure XP purification

165 between each successive round of amplification. Agilent Bioanalyzer dsDNA kit was used to

166 assess purity of the amplified product. 

kit. Each read is sorted into groups according to reaction indices. Then each read is trimmed to minima of 150 length and Q score of 20 (Phred+33 quality score), ensuring that the composite reads will cover the entirety of template sequence. Reads with the same reaction indices are then grouped according to their UMI barcodes and the barcodes are then stripped. Reads originating from the same replicated molecule would share the same UMI barcode, thus consensus for each position was determined by $90 \%$ majority within the UMI family that shares the same base. Bases with less than $90 \%$ majority consensus may contain PCR-induced errors and thus are not included for downstream analysis. Consensus sequence with non-matching bases in the first 5 positions are removed to avoid analysis of mis-primed products. We observed that the apparent error rate for a polymerase decreased and plateaued as consensus number increased, and we picked a minimum of 5 or 10 consensus threshold for each molecule to improve accuracy in replication error calling. Consensus sequence from each UMI family is then aligned to the reference sequence using BWA-MEM ${ }^{26}$. Substitution, insertion, and deletion errors are determined by comparing the consensus sequence of each UMI molecule to the pUC19 reference sequence without counting ambiguous assignments.

\section{Dataset and code availability}

Dataset and code to reproduce the analysis will be available on public repository.

Results:

\section{Psychrophilic DNA polymerases can replicate nucleic acid below zero degree Celsius}

To better understand the effect of temperature-adaptation on polymerase fidelity, we characterized replication error rates of psychrophilic, mesophilic, and thermophilic DNA polymerases across a wide range of reaction temperatures. As no commercial source was

191 available for psychrophilic DNA polymerases, we determined the coding sequences

192 bioinformatically, and optimized a recombinant cloning and purification strategy for DNA 
193 polymerases I and II from Psychromonas ingrahamii, a gram-negative bacteria previously shown 194 to grow and replicate at $-12^{\circ} \mathrm{C}$ in laboratory condition (Supplementary Figure 1a) (Methods) ${ }^{27-}$

$195{ }^{29}$. We named the DNA polymerases I and II from this psychrophilic bacteria as Psychromonas 196 ingrahamii polymerase I (PIPI) and Psychromonas ingrahamii polymerase B (PIPB),

197 respectively. PIPI was purified by maltose affinity column, cleaved off its tandem-fused maltosebinding protein (MBP) tag, and then re-purified with size exclusion chromatography (Methods). As we were unable to obtain a soluble version of PIPB after protease digestion of the fusion tag, we used MBP-PIPB for all of our experiments. A graphical overview of our study is summarized in Figure 1b.

To determine the temperature profile of polymerase replication, we adapted a dsDNA-

203 binding fluorescent dye to detect accumulation of extended products in real-time in the presence

204 of various DNA polymerases at different reaction temperature (Methods). The increase in

205 fluorescence signal over time suggests that our purified psychrophilic polymerases are indeed

206 biochemically active (left panel in Figure 2a). As positive controls for comparison, we show the

207 temperature profiles of Klenow fragment lacking $3{ }^{\prime} \rightarrow 5$ ' exonuclease domain (KleExo-), a

208 mesophilic DNA polymerase (center panel in Figure 2a), and Taq polymerase, a thermophilic

209 DNA polymerase commonly used in molecular assays (right panel in Figure 2a). Consistent

210 with previous report, Klenow and Taq DNA polymerases are maximally active at or above $37^{\circ} \mathrm{C}$

$213^{30,31}$. Intriguingly, PIPI and MBP-PIPB exhibit characteristically distinct temperature profiles for

212 replication activity: PIPI reaches peak polymerase activity at $37^{\circ} \mathrm{C}$, similar to KleExo- (left panel

213 in Figure 2a). As observed previously, the optimal temperature of enzyme activity can differ

214 from the temperature to which the host organism is adapted to ${ }^{31,32}$. On the other hand, polymerase 215 activity of MBP-PIPB is optimal at $20^{\circ} \mathrm{C}$ and becomes inactivated above $30^{\circ} \mathrm{C}$. Combined, our

216 results show that the temperature profiles are distinct for the two psychrophilic DNA

217 polymerases, suggesting a different physiological requirement for their catalytic rates and

218 structural robustness. This may not be surprising as family A and B polymerases are thought to

219 carry out different roles in vivo. 
222 fluorescently labeled, primed M13 phage template (Methods), we measured extension activity of

223 the two psychrophilic DNA polymerases at $-19^{\circ} \mathrm{C}$ in aqueous solution supplemented with $30 \%$

224 glycerol. We discover that PIPI retains higher apparent extension activity as it completed a 5-mer

225 extension within 7 hours, while MBP-PIPB did not (center panel in Figure 2b). MBP-PIPB

226 failed to complete 5-mer extension at $-19^{\circ} \mathrm{C}$ up to 23 hours; however, the product lengths

227 noticeably increased (right panel in Figure 2b). As these two polymerases are predicted to

228 contain 3' $\rightarrow$ 5' exonuclease domains, we also determined their exonuclease activity (Figure 2c).

229 We find that MBP-PIPB can cleave single base on the timescale of minutes at $25^{\circ} \mathrm{C}$, while PIPI

230 fails to cleave at up to 2 hours, suggesting its exonuclease activity is slower than MBP-PIPB or

231 inactive (Supplementary Figure 1b). The exonuclease activity of family B polymerases is

232 thought to play a role in DNA repair. It may help explain the apparent discrepancy in

233 polymerization rate at sub-zero temperature between the two polymerases.

Multiplexed measurement of polymerase error rate across reaction temperature

In order to profile polymerase errors across a range of reaction temperature and conditions, we adapted a high-throughput multiplexed sequencing approach as illustrated in phage template (NEB) is equilibrated to the desired temperature prior to the addition of DNA polymerase. Unless otherwise noted, we have used 3-( $N$-morpholino)propanesulfonic acid (MOPS, $\mathrm{pH} 8.5$ ) to buffer each reaction to $\mathrm{pH}$ changes, which can influence enzyme fidelity independently of temperature ${ }^{33}$. After quenching and removal of the polymerase, the complementary strand is then synthesized with high-fidelity Q5 DNA polymerase to minimize errors introduced in the second strand. Both the first and second strand are synthesized using DNA primers that encode a predefined library index and unique molecular index (UMI) to barcode the identities of each reaction and individual molecules, respectively. The dsDNA products are then PCR amplified, purified, and pooled at equimolar concentrations for

247 sequencing on a MiSeq 2 x 300 bp platform. We found no runoff amplification by-products in up

248 to 26 rounds of PCR amplification, while 20 rounds of PCR amplification failed to yield

249 sufficient DNA amount for downstream purification (Supplementary Figure 2a). The purified

250 libraries are pooled and sequenced on Illumina MiSeq platform. We deconvolved the sequenced 
reads by their reaction indices and UMIs, removed sequencing errors by trimming reads with low

252

253

254

255

256

257

258

259

260

261

262

263

264

265

266

267

268

269

270

271

272

273

274

275

276

277

278

279 quality, and called consensus sequence of molecules as described in Methods. Quantification of base counts with high sequence consensus reveals an uniform coverage along the entire M13 template, indicating no substantial positional effect on measurement dropout.

\section{Reaction temperature increases error rate of psychrophilic and mesophilic DNA}

\section{polymerases}

To quantify the error rate of each polymerase reaction, we determined base mismatch (substitution error) or indel (deletion or insertion error) in each unique molecule. As insertion rate is relatively low, we focused our analysis primarily on substitution and deletion rates of psychrophilic, mesophilic, and thermophilic DNA polymerases in Figures 4a-b. Quantification of Q5 DNA polymerase error rate in its native buffer (Q5NativeBuffer) at $72^{\circ} \mathrm{C}$ provides a baseline for our measurement, revealing an average substitution, deletion, and insertion rates of $4.44 \times 10^{-6}, 9.50 \times 10^{-7}$, and $1.37 \times 10^{-7}$ per base, respectively, which agrees well with previously reported values (Table 1 and right panel in Figure 4a) ${ }^{25,34}$. Phusion (ThermoFisher), another high-fidelity and commonly used thermophilic polymerase, has a similar substitution rate of 5.05 x $10^{-6}$ per base (Table 1) at $72^{\circ} \mathrm{C}$ in its native Phusion HF buffer (PhusionNativeBuffer; ThermoFisher). We discover that the substitution rate of Phusion DNA polymerase increases by more than a factor of two when switched from its native buffer to MOPS, a buffer with low $\Delta \mathrm{pKa} / \Delta \mathrm{T}$ coefficient; furthermore, we notice an increased substitution rate of Phusion polymerase in its native buffer (PhusionNativeBuffer) in lower reaction temperature. As the composition of Phusion native buffer (ThermoFisher) is undisclosed, we postulate the $\Delta \mathrm{pKa} / \Delta \mathrm{T}$ of its buffering reagent may be high and thus its acidity can change substantially upon temperature shift. which leads to changes in Phusion polymerase error rate. This would explain why, relative to the Phusion native buffer, the substitution rate of Phusion in MOPS buffer remains relatively invariant to temperature changes (Table 1 and right panel in Figure 4a). Supporting this hypothesis, we do not observe substantial differences in the substitution rate of Q5 polymerase in MOPS buffer between $30^{\circ} \mathrm{C}$ and $72^{\circ} \mathrm{C}$. Our finding thus suggests that biological assays that involve the use of thermophilic polymerases at low temperature consider the use of alternative buffering agent to ensure optimal fidelity. 

polymerase and mesophilic polymerase error rate. The temperature effect is most dramatic on PIPI and KleExo- whose substitution rate rose by more than 5 and 30 fold, respectively, between reaction temperatures of $10^{\circ} \mathrm{C}$ and $50^{\circ} \mathrm{C}$ (Tables 2-3) (left and center panels in Figures 4a-b).

284 Similarly, the deletion rate also scales positively with reaction temperature for MBP-PIPB, PIPI, and KleExo- (Tables 2-3) (left and center panels in Figures 4a-b). Curiously, the temperature effect on substitution rate of KleLF and T4 polymerases is not monotonic, revealing a maxima of error rate at $37^{\circ} \mathrm{C}$ (center panel in Figures 2b). In general, we find a log linear regression describes well the correlation between substitution and deletion error rates across all polymerases and reaction conditions (Supplementary Figure 2b), while insertion rate occurs at much lower frequency compared to the other error types and remains largely temperature invariant (Tables

1-3). Next, we wondered if the substitution error spectrum is dependent on reaction temperature.

We show that reaction temperature had the strongest effect on substitution spectrum of KleExo-.

As expected, increase in reaction temperature is associated with increased frequency of

transversion relative to transition errors (Figure 4c). Meanwhile, reaction temperature had a weak effect on the substitution spectrum of PIPI and MBP-PIPB and most other polymerases

(Supplementary Figure 2c).

\section{Distinct mutational profiles are driven by polymerase family type} histories would produce error profiles that are similar to each other across the range of reaction temperature we tested. To validate the phylogenetic relations, we aligned the primary peptide sequences of psychrophilic DNA polymerases to polymerases with known family assignment

303 (Supplementary Figure 2d). To analyze the relations between polymerase family and sequence context of substitution errors, we convolved the errors by their corresponding +1 and -1 bases to generate 3-mer error spectrum. We only kept 3-mer errors that occurred at greater than $20 \%$

306 frequency in at least a single reaction, and removed the rest from further analysis. This filtering 307 step allows us to narrow down 60 distinct 3-mer errors ( 32\% of the entire 3-mer spectrum) and 308 focus on errors that are abundant in at least some of the reactions. We normalized the range of 
error rate for each reaction: we divide the 3-mer error rate by error sum within the corresponding reaction and then apply standardization such that the mean and standard deviation of each 3-mer

311 error rate are 0 and 1, respectively. Thus, a high Z-score indicates a particular error motif occurs

312 more frequently in some polymerase reactions than others and vice versa. Hierarchical clustering

313 of the standardized motif error rates reveals that error profiles cluster by the polymerase,

314 indicating good concordance of error profiles for reactions at different temperatures (Figure 5a).

315 Interestingly, we discover that error profiles of polymerase tended to cluster by their

316 phylogenetic homology in which errors generated by families A and B largely separated into

317 distinct clusters regardless of their respective temperature adaptation range. Our results thus

318 provide evidence that conservation of polymerase sequence is coupled to the frequency of error 319 profiles independent of temperature adaptation experience.

To identify mutational profiles that best explain the observed mutational profiles across all the reactions, we performed principal component analysis on the standardized the 3-mer error rate. This led us to identify principal components 1 and 3 that best explained the mutational profiles of the polymerase families. Projecting the data onto these two principal components reveals a natural boundary on this space that separates the mutational profiles between family A and B (Figure 5b). Overall, high principal component 1 score is associated with mutational

326 profile of family B, while high principal component 3 score is associated with that of family A.

327 To identify mutational motifs that best distinguish each polymerase family, we trained a random

328 forest decision tree to classify origin of each 3-mer error motif (Figure 5c). We discover that 329 polymerase family A more frequently produced $\mathrm{A} \rightarrow \mathrm{G}$ transition preceded by $\mathrm{G} / \mathrm{C}$ at -1 position.

330 On the other hand, polymerase family B more frequently produced pyrimidine $(\mathrm{C} / \mathrm{T}) \rightarrow \mathrm{A}$

331 transversion. In addition, the error position is often preceded by a purine (A/G) in the -1 position.

332 This suggests that conserved structural differences between the two polymerase families may

333 underlie the propensity for polymerase to generate distinct mutational signatures. 


\section{Discussion:}

336

337

338

339

340

341

342

343

344

345

346

347

348

349

350

351

352

353

354

355

356

357

358

359

360

361

362

363

DNA polymerases are the biological machinery underlying transmission of genetic information and hold the key to many biotechnological innovations. While the majority of studies have focused on polymerases of mesophilic or thermophilic origins, we are one of the first to provide a comprehensive biochemical characterization of activity and fidelity of bacterial DNA polymerases across a wide temperature adaptation range. To our knowledge, this is the first demonstration that DNA extension can be accomplished with psychrophilic DNA polymerases below water's freezing temperature $\left(0^{\circ} \mathrm{C}\right)$. This opens the door towards enabling more efficient nucleic acid amplification techniques directly on cryopreserved samples ${ }^{37}$. Reaction at low temperature is desirable as it can inhibit mammalian nuclease activity and reduce phototoxicity and DNA damages ${ }^{23,38}$. Thus, the development of low temperature biotechnology should in theory enable more accurate and precise measurement of biological attributes at a state that is closer to the "ground-truth". Ice may also provide an unexpected environment for biological reactions. As early as 1964, groups have observed that biochemical reactions can be substantially catalyzed in partially frozen aqueous system due to increased concentration of reactant in the aqueous portions. These observations suggest that ice slurry may be an unexpected environment for the origin of living systems ${ }^{39-42}$. Combined with cold-active enzymes, dynamic modulation of liquid-frozen phase may provide an under-exploited niche for biotechnology applications ${ }^{43,44}$.

In this study, we have also explored one of the long standing questions in enzymology is there a necessary trade-off between substrate specificity and activity? To address this question, we biochemically characterized bacterial DNA polymerase adapted to a wide range of environmental temperatures. Our results suggest that distinct temperature adaptation can differentially alter how the stability, kinetics, and fidelity of DNA polymerases change in response to fluctuations of environmental temperature. Our data shows that psychrophilic polymerases are more heat labile while thermophilic polymerases are largely heat resistant, as consistent with previous reports of other psychrophilic enzymes ${ }^{45}$. Furthermore, increased reaction temperature substantially increased the error rate of psychrophilic DNA polymerases and E. coli DNA polymerase I (Klenow fragments) but not that of thermophilic polymerases such as Phusion and Q5. Nucleic acid analogues are of interest to a wide range of synthetic 
364 biology and biological engineering research as a mean to expand orthogonal signals or building

365 parts $^{46}$. Most often, this is achieved through a combination of rational engineering and directed

366 evolution on mesophilic or thermophilic polymerase templates ${ }^{47-50}$. Our results shown here

367 suggest that using cold-adapted polymerases as a starting template may achieve higher substrate

368 promiscuity and thus greater incorporation rate of unnatural nucleotides. This holds the

369 possibility to improve most sequencing-by-synthesis sequencers available on the market as well

370 as accelerating the application of nucleic acids analogues. 


\section{Acknowledgments:}

374 YX thanks professors James Berger and Daniel Herschlag for helpful advices and

375 discussions. YX thanks Richard Pfuetzner, Steven Wilson, Qiangjun Zhou, and Austin Wang for

376 sharing equipment and suggestions. YX thanks Norma Neff, Fabio Zanini, Felix Horns, Derek

377 Croote, Mark Kowarsky, Brian Yu, Bojk Berghuis, and Nimit Jain for discussions and

378 suggestions. 
380 Table 1. Error rates (per base) for thermophilic DNA polymerases.

\begin{tabular}{|c|c|c|c|c|c|}
\hline Origin & Reaction & $\begin{array}{c}\text { Temperature } \\
\left({ }^{\circ} \mathrm{C}\right)\end{array}$ & $\begin{array}{c}\text { Substitution rate } \\
\left.\text { (base }^{-1}\right)\end{array}$ & $\begin{array}{l}\text { Deletion rate } \\
\quad\left(\text { base }^{-1}\right)\end{array}$ & $\begin{array}{c}\text { Insertion rate } \\
\quad\left(\text { base }^{-1}\right)\end{array}$ \\
\hline \multirow{11}{*}{ Thermophile } & $\mathrm{Q}^{\mathrm{NB}}$ & 72 & $4.44 \times 10^{-6}$ & $9.50 \times 10^{-7}$ & $1.37 \times 10^{-7}$ \\
\hline & Q5 & 30 & $6.04 \times 10^{-6}$ & $7.45 \times 10^{-7}$ & $5.31 \times 10^{-7}$ \\
\hline & Q5 & 72 & $5.38 \times 10^{-6}$ & $1.56 \times 10^{-7}$ & $5.05 \times 10^{-8}$ \\
\hline & Taq & 30 & $6.32 \times 10^{-5}$ & $2.27 \times 10^{-6}$ & $2.01 \times 10^{-6}$ \\
\hline & Taq & 50 & $2.18 \times 10^{-4}$ & $2.18 \times 10^{-5}$ & $3.53 \times 10^{-6}$ \\
\hline & Phusion $^{\mathrm{NB}}$ & 30 & $2.51 \times 10^{-5}$ & $1.82 \times 10^{-8}$ & $8.32 \times 10^{-7}$ \\
\hline & Phusion $^{\mathrm{NB}}$ & 50 & $8.11 \times 10^{-6}$ & ND & $1.95 \times 10^{-6}$ \\
\hline & Phusion $^{\mathrm{NB}}$ & 72 & $5.05 \times 10^{-6}$ & ND & $9.30 \times 10^{-8}$ \\
\hline & Phusion & 30 & $2.02 \times 10^{-5}$ & $2.32 \times 10^{-6}$ & $4.81 \times 10^{-7}$ \\
\hline & Phusion & 50 & $3.64 \times 10^{-5}$ & $2.46 \times 10^{-6}$ & $4.84 \times 10^{-7}$ \\
\hline & Phusion & 72 & $1.24 \times 10^{-5}$ & $3.36 \times 10^{-7}$ & $5.11 \times 10^{-7}$ \\
\hline
\end{tabular}

$381 \quad{ }^{\mathrm{NB}}=$ reaction carried out in native buffer supplied by the manufacturer.

$382 \quad{ }^{\mathrm{ND}}=$ Error frequency below the detectable error baseline. 
384 Table 2. Error rates (per base) for psychrophilic DNA polymerases.

\begin{tabular}{|c|c|c|c|c|c|}
\hline Origin & Reaction & $\begin{array}{c}\text { Temperature } \\
\left({ }^{\circ} \mathbf{C}\right)\end{array}$ & $\begin{array}{c}\text { Substitution rate } \\
\left(\text { base }^{-1}\right)\end{array}$ & $\begin{array}{c}\text { Deletion rate } \\
\left(\text { base }^{-1} \text { ) }\right.\end{array}$ & $\begin{array}{c}\text { Insertion rate } \\
\text { (base }^{-1} \text { ) }\end{array}$ \\
\hline & MBP-PIPB & 10 & $9.52 \times 10^{-6}$ & $1.84 \times 10^{-6}$ & $1.26 \times 10^{-6}$ \\
MBP-PIPB & 20 & $2.55 \times 10^{-5}$ & $2.20 \times 10^{-5}$ & $1.09 \times 10^{-6}$ \\
Psychrophile & PIPI & 10 & $3.87 \times 10^{-5}$ & $1.48 \times 10^{-6}$ & $1.62 \times 10^{-7}$ \\
& PIPI & 20 & $6.34 \times 10^{-5}$ & $4.15 \times 10^{-6}$ & $2.20 \times 10^{-7}$ \\
& PIPI & 37 & $1.83 \times 10^{-4}$ & $1.59 \times 10^{-5}$ & $\mathrm{ND}$ \\
& PIPI & 50 & $2.11 \times 10^{-4}$ & $8.47 \times 10^{-6}$ & $\mathrm{ND}$
\end{tabular}

$385{ }^{\mathrm{ND}}=$ Error frequency below the detectable error baseline. 
386 Table 3. Error rates (per base) for mesophilic DNA polymerases.

\begin{tabular}{|c|c|c|c|c|c|}
\hline Origin & Reaction & $\begin{array}{c}\text { Temperature } \\
\left({ }^{\circ} \mathrm{C}\right)\end{array}$ & $\begin{array}{c}\text { Substitution rate } \\
\text { (base }^{-1} \text { ) }\end{array}$ & $\begin{array}{l}\text { Deletion rate } \\
\quad\left(\text { base }^{-1}\right)\end{array}$ & $\begin{array}{c}\text { Insertion rate } \\
\quad\left(\text { base }^{-1}\right)\end{array}$ \\
\hline & KleExo- & 10 & $4.20 \times 10^{-5}$ & $7.65 \times 10^{-6}$ & $3.38 \times 10^{-7}$ \\
\hline & KleExo- & 20 & $6.91 \times 10^{-5}$ & $8.55 \times 10^{-6}$ & ND \\
\hline & KleExo- & 37 & $1.07 \times 10^{-3}$ & $1.75 \times 10^{-4}$ & $4.39 \times 10^{-7}$ \\
\hline & KleExo- & 50 & $1.38 \times 10^{-3}$ & $1.94 \times 10^{-4}$ & $3.38 \times 10^{-6}$ \\
\hline & KleLF & 10 & $8.53 \times 10^{-6}$ & ND & $2.29 \times 10^{-8}$ \\
\hline \multirow[t]{6}{*}{ Mesophile } & KleLF & 20 & $1.56 \times 10^{-5}$ & $1.12 \times 10^{-7}$ & $2.14 \times 10^{-7}$ \\
\hline & KleLF & 37 & $2.99 \times 10^{-5}$ & $1.20 \times 10^{-7}$ & $1.43 \times 10^{-7}$ \\
\hline & KleLF & 50 & $2.00 \times 10^{-5}$ & ND & $5.45 \times 10^{-8}$ \\
\hline & $\mathrm{T} 4$ & 10 & $3.25 \times 10^{-5}$ & $1.32 \times 10^{-6}$ & $2.37 \times 10^{-8}$ \\
\hline & $\mathrm{T} 4$ & 37 & $5.92 \times 10^{-5}$ & $1.17 \times 10^{-6}$ & ND \\
\hline & $\mathrm{T} 4$ & 50 & $1.45 \times 10^{-5}$ & ND & ND \\
\hline
\end{tabular}

$387 \quad{ }^{\mathrm{ND}}=$ Error frequency below the detectable error baseline. 

available under aCC-BY-ND 4.0 International license.

388 Figure 1. (a) A schematic illustrating the apparent trade-off between enzymatic speed versus 389 fidelity in the context of temperature adaptation. (b) Graphical summary of the study. 
390 Figure 2. (a) Normalized extension speed of purified psychrophilic, mesophilic, and

391 thermophilic DNA polymerases measured by a fluorometric assay. (b) Extension activity of 392 purified psychrophilic DNA polymerases carried out at $-19^{\circ} \mathrm{C}$ for 7 or 23 hours on a template 393 with 5 base gap. (c) Exonuclease activity of psychrophilic DNA polymerases carried out at room 394 temperature for 5, 10, or 20 minutes. Both measurements were repeated at least twice in two 395 independent experiments. 
397 Figure 3. (a) A schematic illustrating the experimental overview of multiplexed single-molecule 398 measurement of polymerase error rate at various reaction temperature. Replication errors 399 (highlighted by blue cross) are distinguished from sequencing errors (highlighted by orange 400 cross) by comparing consensus sequence of individual molecules to the reference sequence of 401 M13 phage template. 
402 Figure 4. Substitution (a) and deletion (b) error rates of psychrophilic (left), mesophilic (center), 403 and thermophilic (right) DNA polymerases as a function of reaction temperature. (c) 404 Temperature-dependent variation in substitution spectrum across MBP-PIPB (left), PIPI (center), 405 and KleExo- (right) polymeases. 
406 Figure 5. (a) Heatmap of standardized 3-mer substitution rates ordered by hierarchical 407 clustering. (b) Projection of polymerase reactions by principal components (PCs) 1 and 3 of 408 standardized 3-mer substitution rates. Each dot is colored by the corresponding DNA polymerase 409 and annotated with the reaction temperature. Dotted line is identity of PC1 and PC3 which 410 separates substitution profiles between polymerase family A and B. (c) Motifs that distinguish 411 error profiles between polymerase families A (blue) and B (red) are predicted by random forest 412 classifier. Motifs predicted to have zero weights are removed and next we showcase here the top 413 motifs with a difference in standard Z-score greater than 1. Logo plots reflect the frequency of 414 non-zero weighted mutation motifs at $-1,0$, and +1 positions that are enriched in polymerase 415 families A (top) or B (bottom). 
416 Supplementary Figure 1. (a) SDS-PAGE analysis of purified DNA polymerases. Lane L: 417 PrecisionPlus Ladder (Bio-rad). Lane 1: MBP-paramyosin protein control (NEB). Lane 2: 418 Klenow Exo- (NEB). Lane 3: Klenow LF (NEB). Lane 4: Q5 (NEB). Lane 5: Taq (NEB). Lane 419 6: MBP-PIPB (134.8 kDa). Lane 7: PIPI (69.9 kDa). (b) Exonuclease activity assay of PIPI and 420 MBP-PIPB at $25^{\circ} \mathrm{C}$ for 2 hours. 
421 Supplementary Figure 2. (a) High-sensitivity Bioanalyzer DNA (Agilent) assay of replicated 422 products after 20 or 26 rounds of PCR amplification in the flow-through (FT) or elution fractions 423 of Ampure purification output. (b) Deletion and substitution rate (per base) is correlated as 424 modeled by linear regression $\left(r^{2}: 0.98\right)$. (c) Substitution spectrum of mesophilic and thermophilic 425 DNA polymerases across reaction temperature. (d) Multiple sequence alignment (Clustal 426 Omega) of peptide sequences for polymerases used in this study. While Phusion DNA 427 polymerase sequence is undisclosed, it is expected to be a derivative of Pyrococcus DNA 428 polymerase II (Pfu). Family A cluster consists of Taq, PIPI, and Klenow polymerases. Family B 429 polymerases consist of T4, Pfu, and PIPB. 


\section{Corresponding Author}

431 *Stephen R. Quake (steve@ quake-lab.org)

\section{Funding Sources}

433 YX is supported by the Stanford Interdisciplinary Graduate Fellowship and Weiland Family

434 Fellowship. IB acknowledges support from Stanford University and from The Hebrew

435 University of Jerusalem. SRQ is supported by the Chan Zuckerberg Biohub. 


\section{References}

438

439 1. Ratkowsky, D. A., Olley, J., McMeekin, T. A. \& Ball, A. Relationship between 440 temperature and growth rate of bacterial cultures. J. Bacteriol. 149, 1-5 (1982).

441 2. Ingraham, J. L. \& Stokes, J. L. Psychrophilic Bacteria. J. Bacteriol. 76, 75-80 (1958).

442 3. Svingor, Á., Kardos, J., Hajdú, I., Németh, A. \& Závodszky, P. A better enzyme to cope 443 with cold: Comparative flexibility studies on psychrotrophic, mesophilic, and thermophilic IPMDHS. J. Biol. Chem. 276, 28121-28125 (2001).

4. Ingraham, J. L. \& Bailey, G. F. Comparative Study of Effect of Temperature on

5. Wintrode, P. L., Miyazaki, K. \& Arnold, F. H. Cold adaptation of a mesophilic subtilisin-

6. Lonhienne, T., Gerday, C. \& Feller, G. Psychrophilic enzymes: Revisiting the thermodynamic parameters of activation may explain local flexibility. Biochim. Biophys. Acta - Protein Struct. Mol. Enzymol. 1543, 1-10 (2000).

7. Lonhienne, T. et al. Modular structure, local flexibility and cold-activity of a novel

8. Liang, Z. X. et al. Evidence for increased local flexibility in psychrophilic alcohol

9. Miyazaki, K., Wintrode, P. L., Grayling, R. A., Rubingh, D. N. \& Arnold, F. H. Directed evolution study of temperature adaptation in a psychrophilic enzyme. J. Mol. Biol. 297, 1015-1026 (2000).

10. Nguyen, V. et al. Evolutionary drivers of thermoadaptation in enzyme catalysis. 294, 289-

11. Tsigos, I., Velonia, K., Smonou, I. \& Bouriotis, V. Purification and characterization of an alcohol dehydrogenase from the Antarctic psychrophile Moraxella sp. TAE123. Eur. J. Biochem. 254, 356-362 (1998).

12. D’Amico, S., Sohier, J. S. \& Feller, G. Kinetics and Energetics of Ligand Binding 
468 13. Loeb, L. A. \& Monnat, R. J. DNA polymerases and human disease. Nat. Rev. Genet. 9, $469 \quad$ 594-604 (2008).

470 14. Copeland, W. C. Inherited Mitochondrial Diseases of DNA Replication. Annu. Rev. Med. 59, 131-146 (2008).

15. Broughton, B. C. et al. Molecular analysis of mutations in DNA polymerase $\eta$ in xeroderma pigmentosum-variant patients. Proc. Natl. Acad. Sci. U. S. A. 99, 815-820 (2002).

16. Donigan, K. A. et al. Human POLB gene is mutated in high percentage of colorectal tumors. J. Biol. Chem. 287, 23830-23839 (2012).

17. Cabelof, D. C. et al. Haploinsufficiency in DNA polymerase $\beta$ increases cancer risk with age and alters mortality rate. Cancer Res. 66, 7460-7465 (2006).

18. Aschenbrenner, J. \& Marx, A. DNA polymerases and biotechnological applications. Curr. Opin. Biotechnol. 48, 187-195 (2017).

19. Dean, F. B., Nelson, J. R., Giesler, T. L. \& Lasken, R. S. Rapid amplification of plasmid and phage DNA using Phi29 DNA polymerase and multiply-primed rolling circle amplification. Genome Res. 11, 1095-1099 (2001).

20. Chen, M. et al. Comparison of Multiple Displacement Amplification (MDA) and Multiple Annealing and Looping-Based Amplification Cycles (MALBAC) in single-cell sequencing. PLoS One 9, 1-12 (2014).

21. Schmitt, M. W. et al. Detection of ultra-rare mutations by next-generation sequencing. Proc. Natl. Acad. Sci. U. S. A. 109, 14508-14513 (2012).

22. Smith, T., Heger, A. \& Sudbery, I. UMI-tools: Modeling sequencing errors in Unique (2017).

23. Potapov, V. \& Ong, J. L. Examining sources of error in PCR by single-molecule sequencing. PLoS One 12, 1-19 (2017).

24. Hammarstrom, M., Hellgren, N., Van den Berg, S., Berglund, H. \& Hard, T. Rapid 495 screening for improved solubility of small human proteins produced as fusion proteins in Escherichia coli. Protein Sci. xx-xxv (2001) doi:10.4018/978-1-4666-6371-8.

497 25. Lee, D. F., Lu, J., Chang, S., Loparo, J. J. \& Xie, X. S. Mapping DNA polymerase errors 498 by single-molecule sequencing. Nucleic Acids Res. 44, e118 (2016). 
499 26. Li, H. Aligning sequence reads, clone sequences and assembly contigs with BWA-MEM.

$500 \quad$ 00, 1-3 (2013).

501 27. Breezee, J., Cady, N. \& Staley, J. T. Subfreezing growth of the sea ice bacterium

502 'Psychromonas ingrahamii'. Microb. Ecol. 47, 300-304 (2004).

503 28. Auman, A. J., Breeze, J. L., Gosink, J. J., Kämpfer, P. \& Staley, J. T. Psychromonas

29. Riley, M. et al. Genomics of an extreme psychrophile, Psychromonas ingrahamii. BMC

30. Lawyer, F. C. et al. High-level expression, purification, and enzymatic characterization of full-length Thermus aquaticus DNA polymerase and a truncated form deficient in 5' to 3' exonuclease activity. Genome Res. 2, 275-287 (1993).

31. Brown, H. S. \& Licata, V. J. Enthalpic switch-points and temperature dependencies of DNA binding and nucleotide incorporation by Pol i DNA polymerases. Biochim. Biophys. Acta - Proteins Proteomics 1834, 2133-2138 (2013).

32. Piotrowski, Y., Gurung, M. K. \& Larsen, A. N. Characterization and engineering of a DNA polymerase reveals a single amino-acid substitution in the fingers subdomain to

33. Ling, L. L., Keohavong, P., Dias, C. \& Thilly, W. G. Optimization of the polymerase increase strand-displacement activity of A-family prokaryotic DNA polymerases. $B M C$ Mol. Cell Biol. 20, 1-11 (2019).

34. Pezza, J. A., Kucera, R. \& Sun, L. Polymerase Fidelity: What is it, and what does it mean chain reaction with regard to fidelity: Modified T7, Taq, and vent DNA polymerases.

35. de Paz, A. M. et al. High-resolution mapping of DNA polymerase fidelity using nucleotide imbalances and next-generation sequencing. Nucleic Acids Res. 46, e78 (2018).

36. Schroeder, J. W., Hirst, W. G., Szewczyk, G. A. \& Simmons, L. A. The Effect of Local Strands. Curr. Biol. 26, 692-697 (2016). and tissues. Genome Biol. 18, 1-15 (2017). 
530 38. Adam, M., Potter, A. S. \& Potter, S. S. Psychrophilic proteases dramatically reduce single-cell RNA-seq artifacts: A molecular atlas of kidney development. Dev. 144, 36253632 (2017).

533

534

535

536

537

538

539

540

541

542

543

544

545

546

547

548

549

550

551

552

553

554

555

556

557

558

559

39. Butler, A. R. \& Bruice, T. C. Catalysis in Water and Ice. A Comparison of the Kinetics of Hydrolysis of Acetic Anhydride, $\beta$-Propiolactone, and p-Nitrophenyl Acetate and the Dehydration of 5-Hydro-6-hydroxydeoxyuridine in Water and in Ice. J. Am. Chem. Soc. 86, 313-319 (1964).

40. Bruice, T. C. \& Butler, A. R. Catalysis in Water and Ice. II.1 The Reaction of Thiolactones with Morpholine in Frozen Systems. J. Am. Chem. Soc. 86, 4104-4108 (1964).

41. Alburn, H. E. \& Grant, N. H. Reactions in Frozen Systems. II.1 Enhanced Hydroxylaminolysis of Simple Amides. J. Am. Chem. Soc. 87, 4174-4177 (1965).

42. Grant, N. H. Biochemical Reactions In Essentially Nonaqueous Systems. 6, 182-187 (1969).

43. Hobbs, P. V. Ice Physics. (Oxford University Press, 2010).

44. Preis, S. G. et al. Labyrinth ice pattern formation induced by near-infrared irradiation. Sci. Adv. 5, (2019).

45. Siddiqui, K. S. \& Cavicchioli, R. Cold-Adapted Enzymes. Annu. Rev. Biochem. 75, 403433 (2006).

46. Hirao, I. et al. An unnatural hydrophobic base pair system: Site-specific incorporation of nucleotide analogs into DNA and RNA. Nat. Methods 3, 729-735 (2006).

47. Gardner, A. F. et al. Therminator DNA Polymerase: Modified nucleotides and unnatural substrates. Front. Mol. Biosci. 6, 1-9 (2019).

48. Chen, T. \& Romesberg, F. E. Directed polymerase evolution. FEBS Lett. 588, 219-229 (2014).

49. Xia, G. et al. Directed evolution of novel polymerase activities: mutation of a DNA polymerase into an efficient RNA polymerase. Proc. Natl. Acad. Sci. U. S. A. 99, 6597602 (2002).

50. Laos, R., Thomson, J. M. \& Benner, S. A. DNA polymerases engineered by directed evolution to incorporate nonstandard nucleotides. Front. Microbiol. 5, 1-14 (2014). 
a

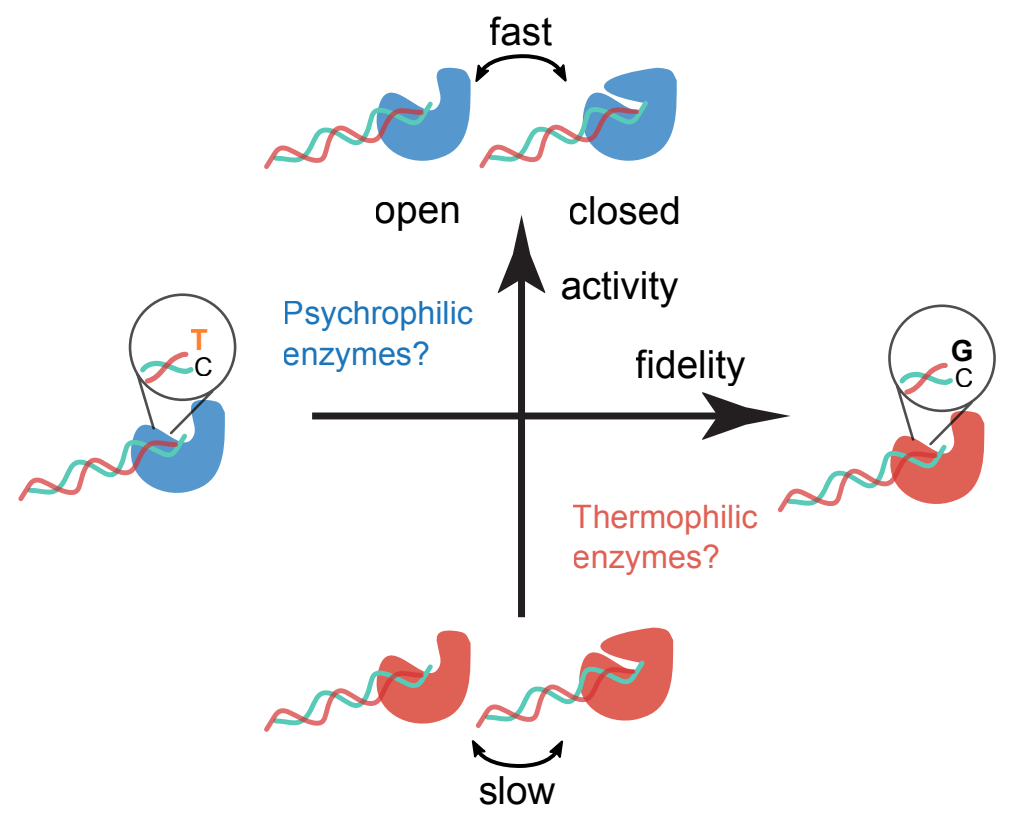

b

JGI

Integrated microbial genomes

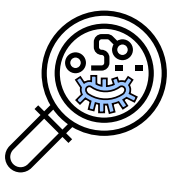

identify psychrophililc

DNA polymerase sequences
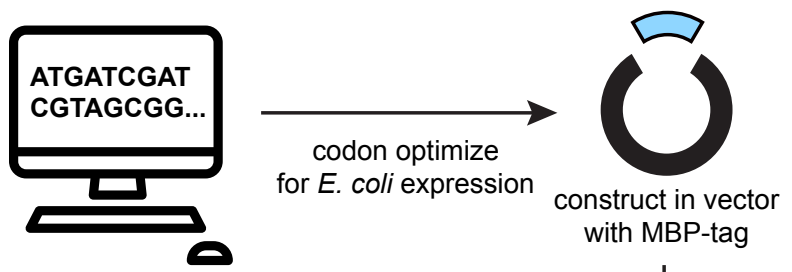

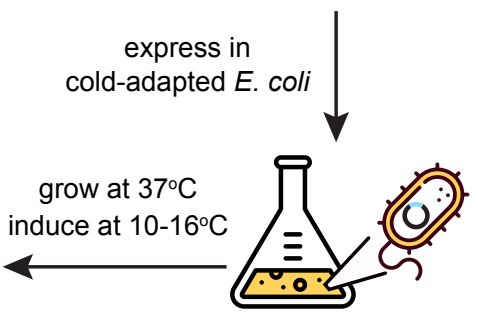

measure

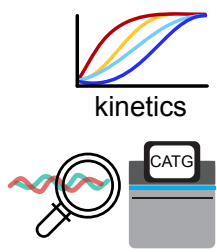

error rate
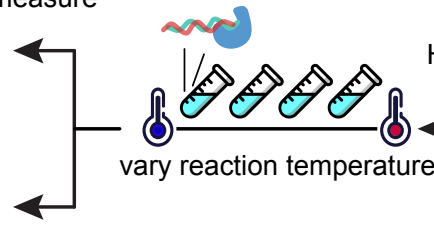

HPLC purification tag-removal

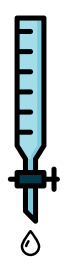


Figure 2

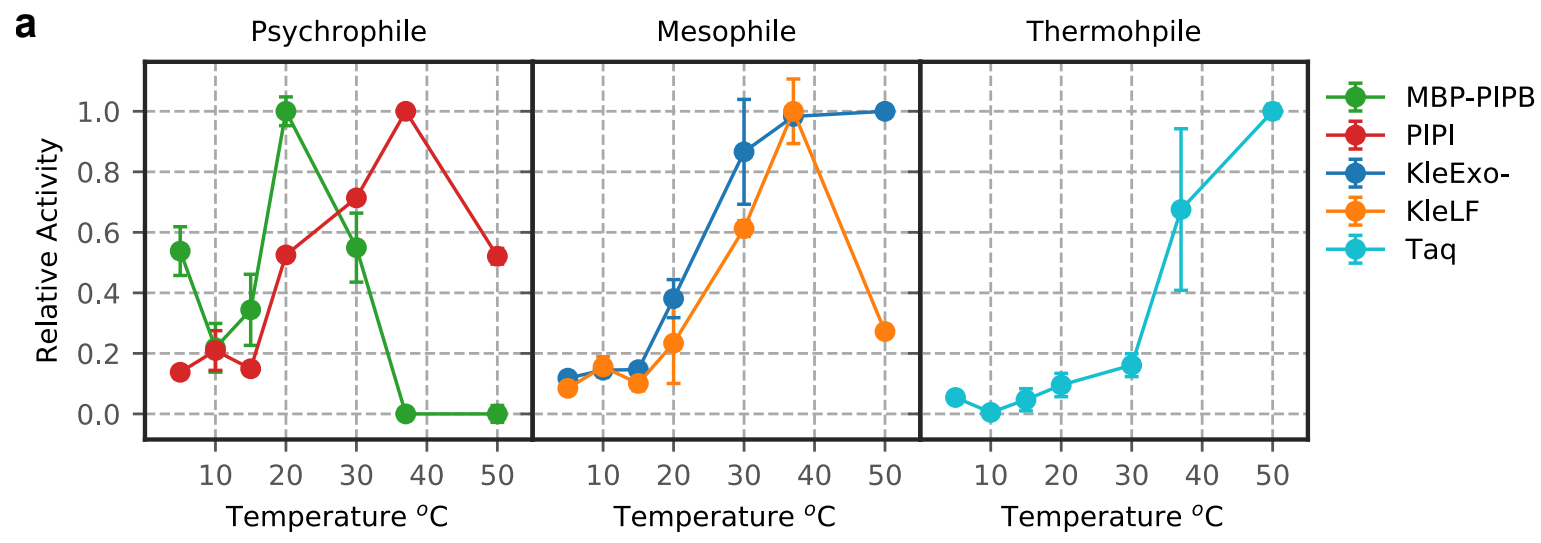

b

C
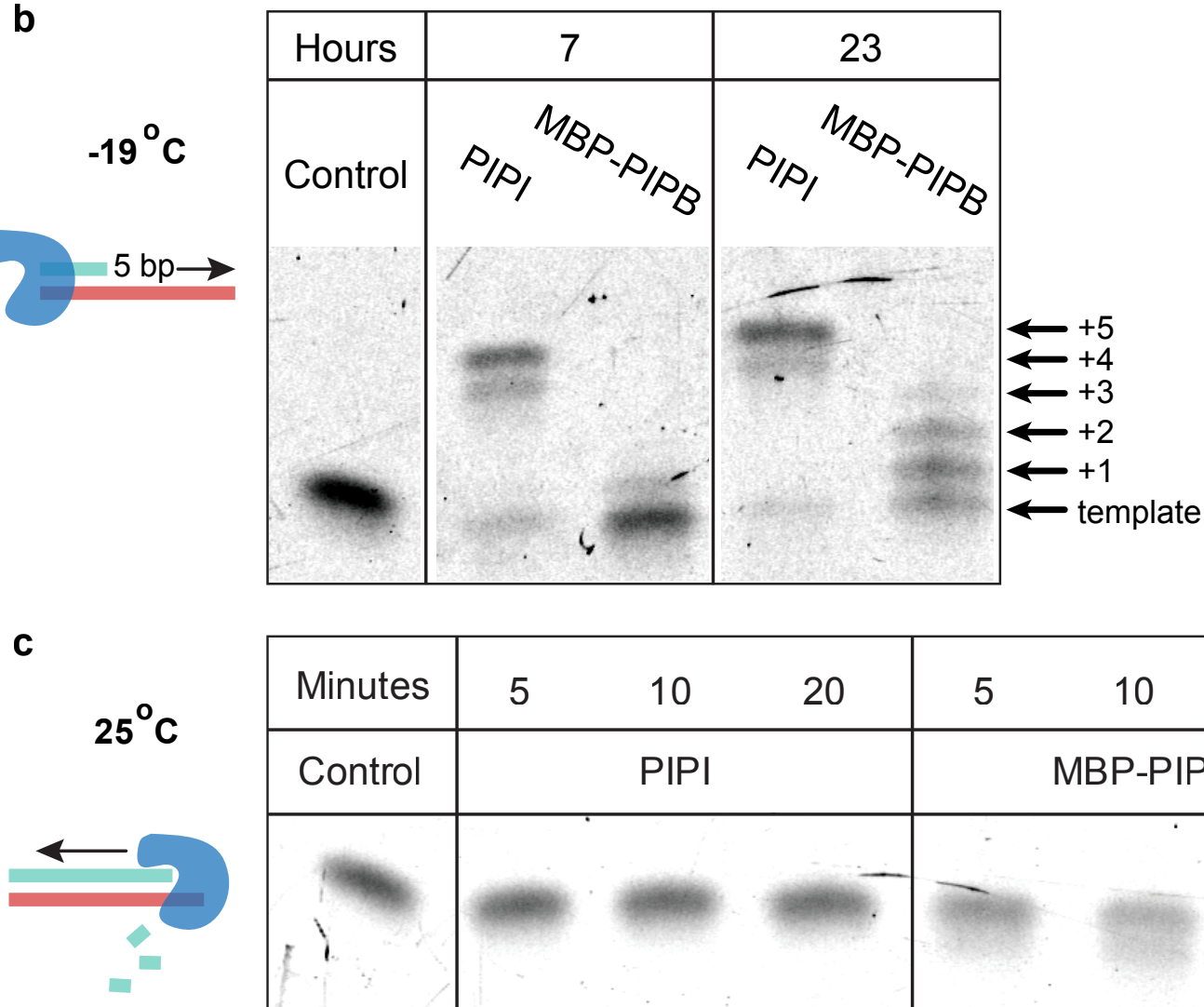

\begin{tabular}{|l|lll|lll|}
\hline Minutes & 5 & 10 & 20 & 5 & 10 & 20 \\
\hline Control & & PIPI & \multicolumn{3}{|c|}{ MBP-PIPB } \\
\hline \multirow{2}{*}{} & & & & & & \\
\hdashline & & & & & & \\
\hline
\end{tabular}




\section{Figure 3}

\section{experimental overview}

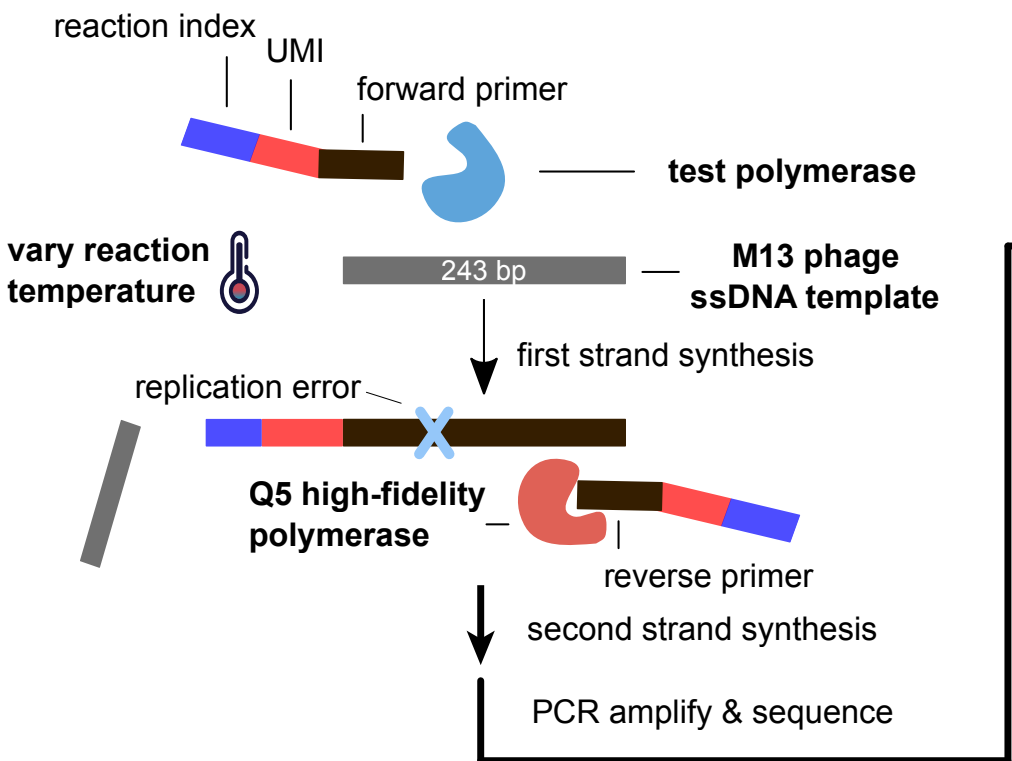

\section{computational overview}

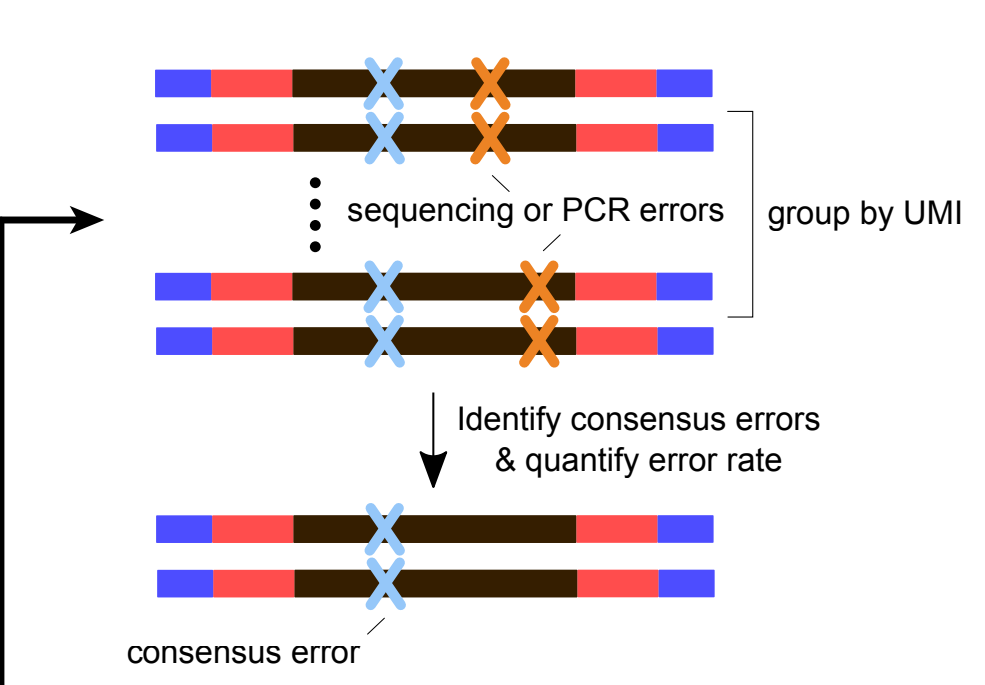




\section{Figure 4}

a

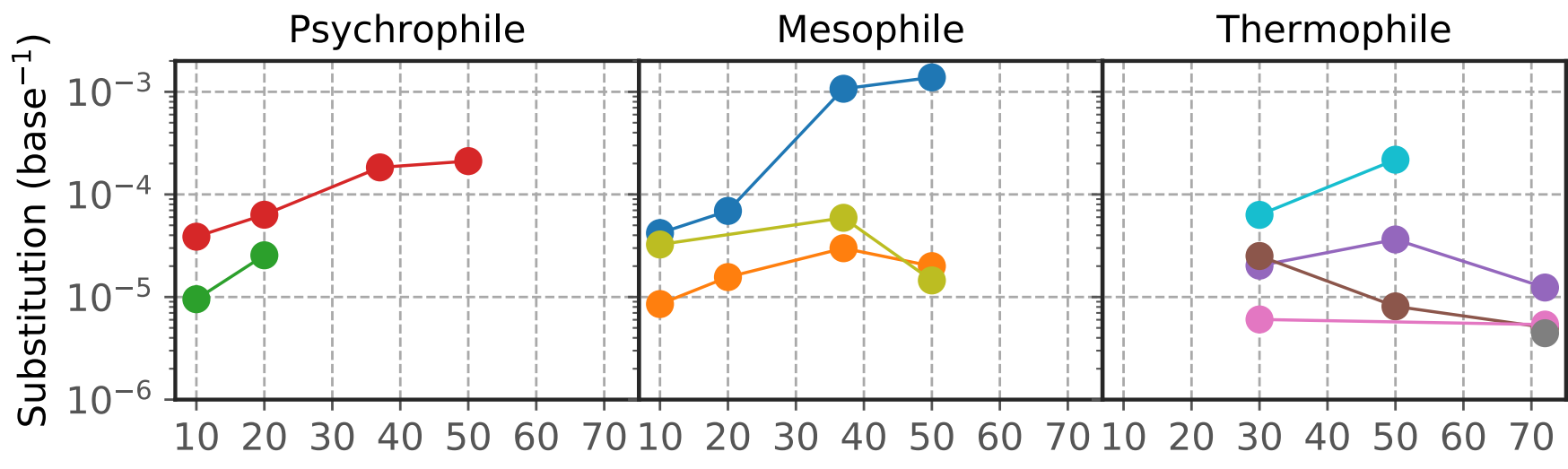

Mesophile

MBP-PIPB

PIPI

KleExo-

KleLF

T4

Phusion

PhusionNativeBuffer

Q5

Q5NativeBuffer Taq

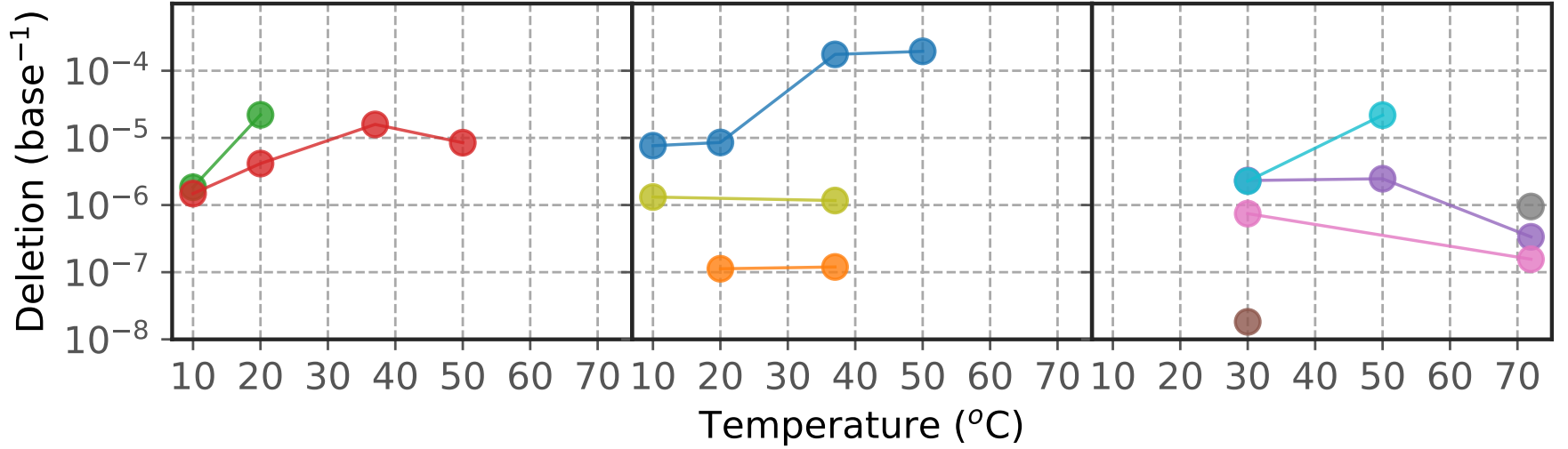

C

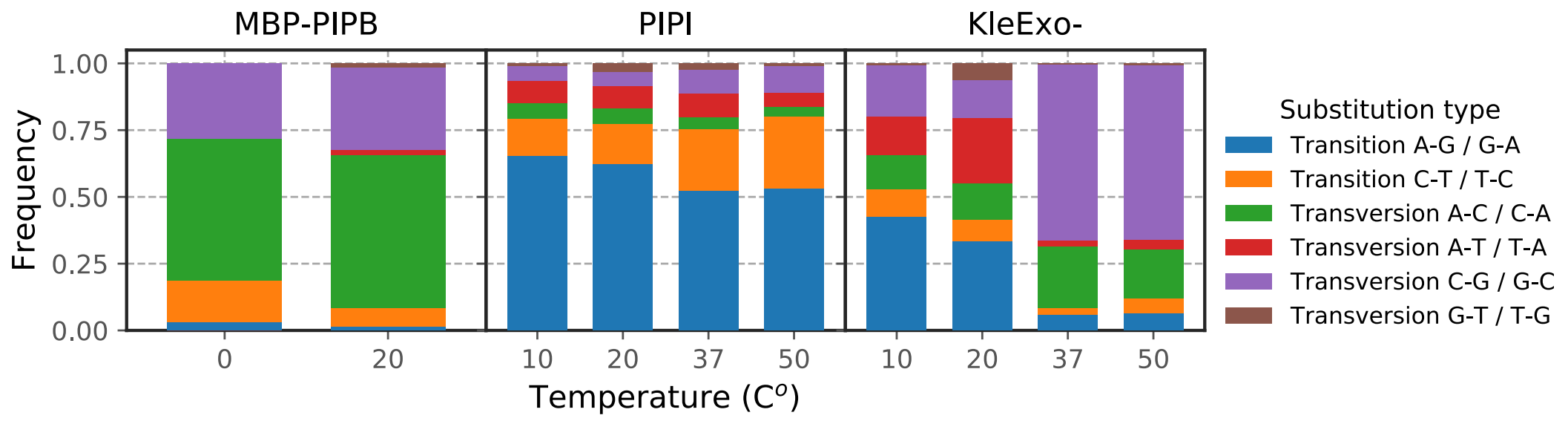


Figure 5

a

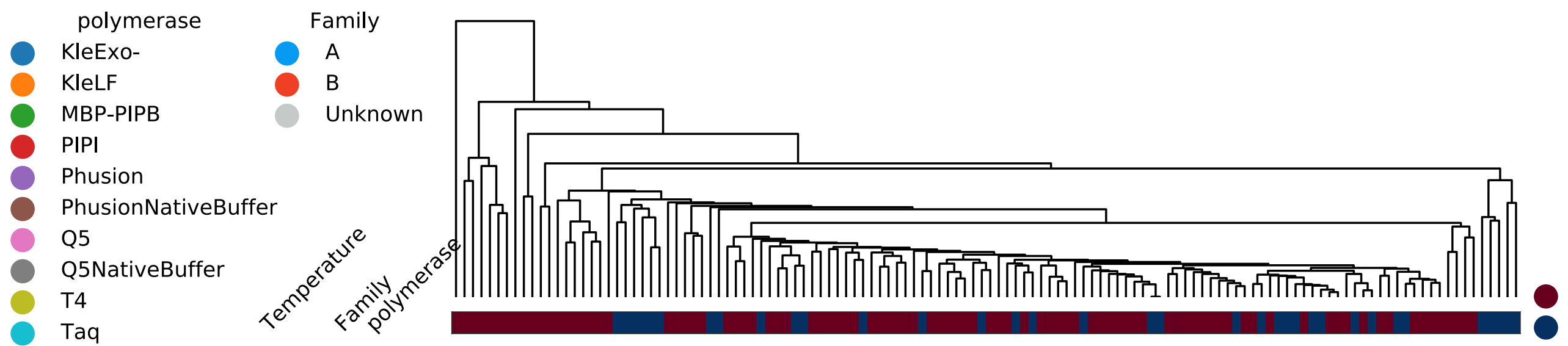

Mutations

- Transition

Taq

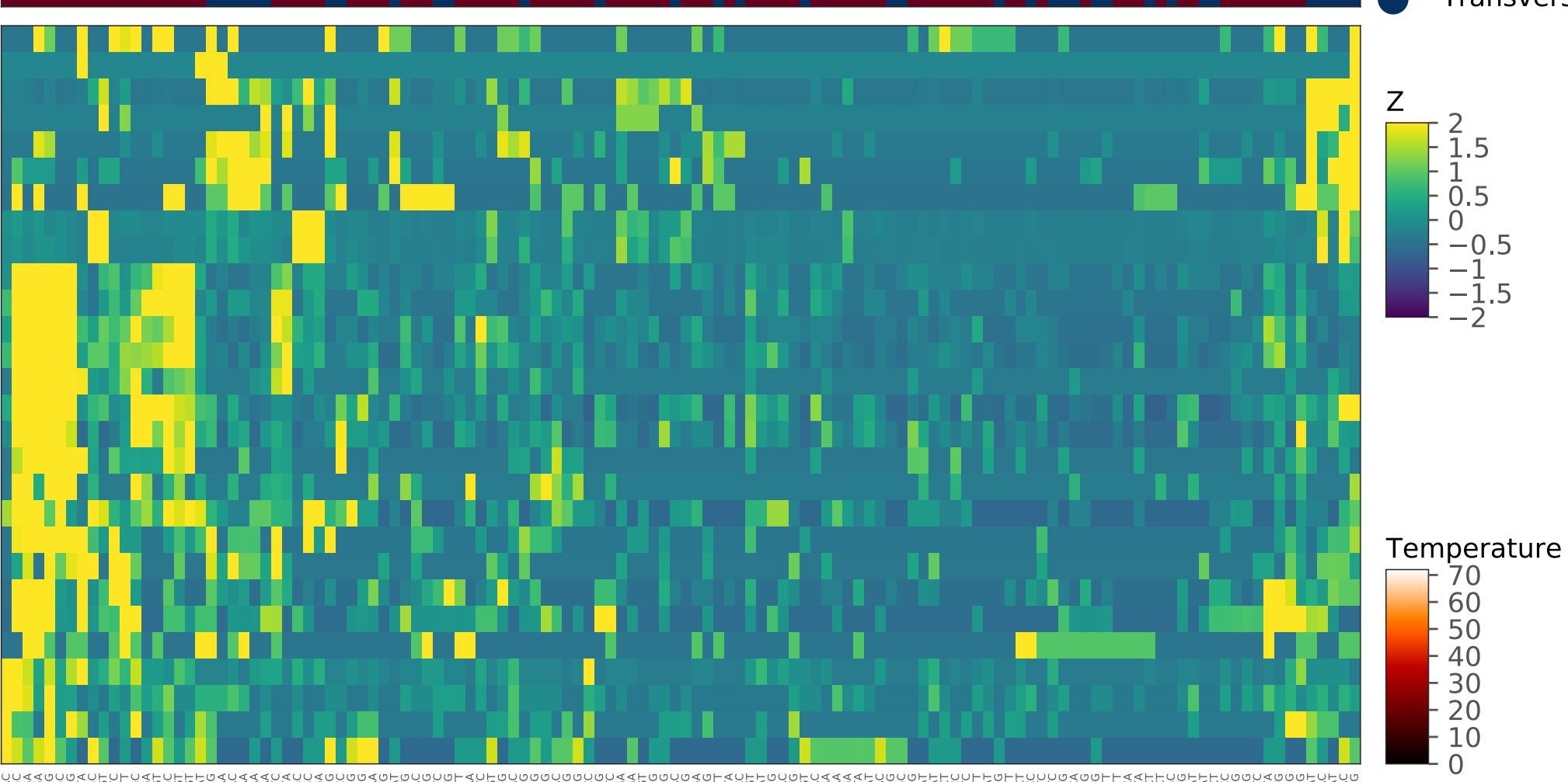

b

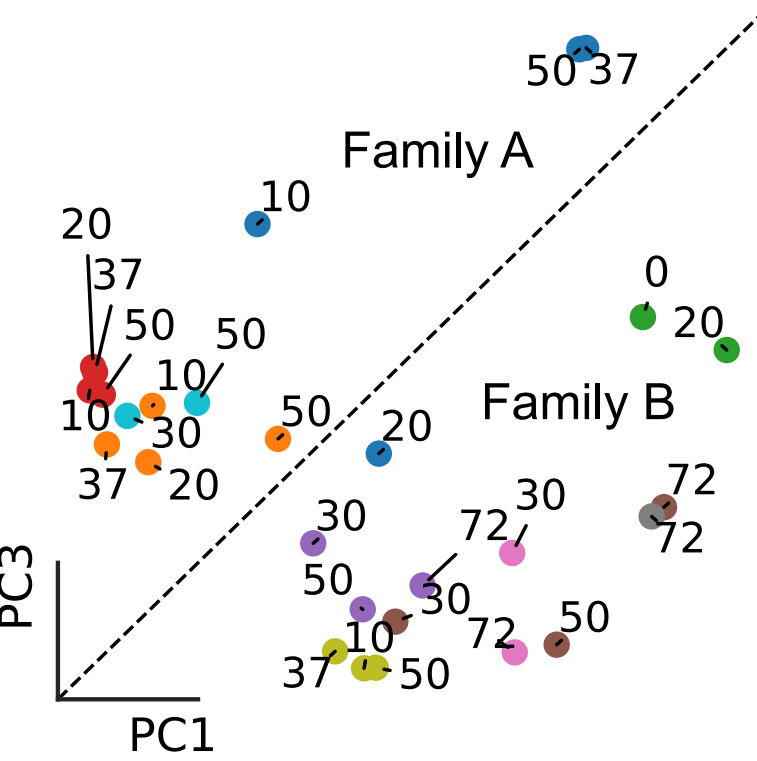

c

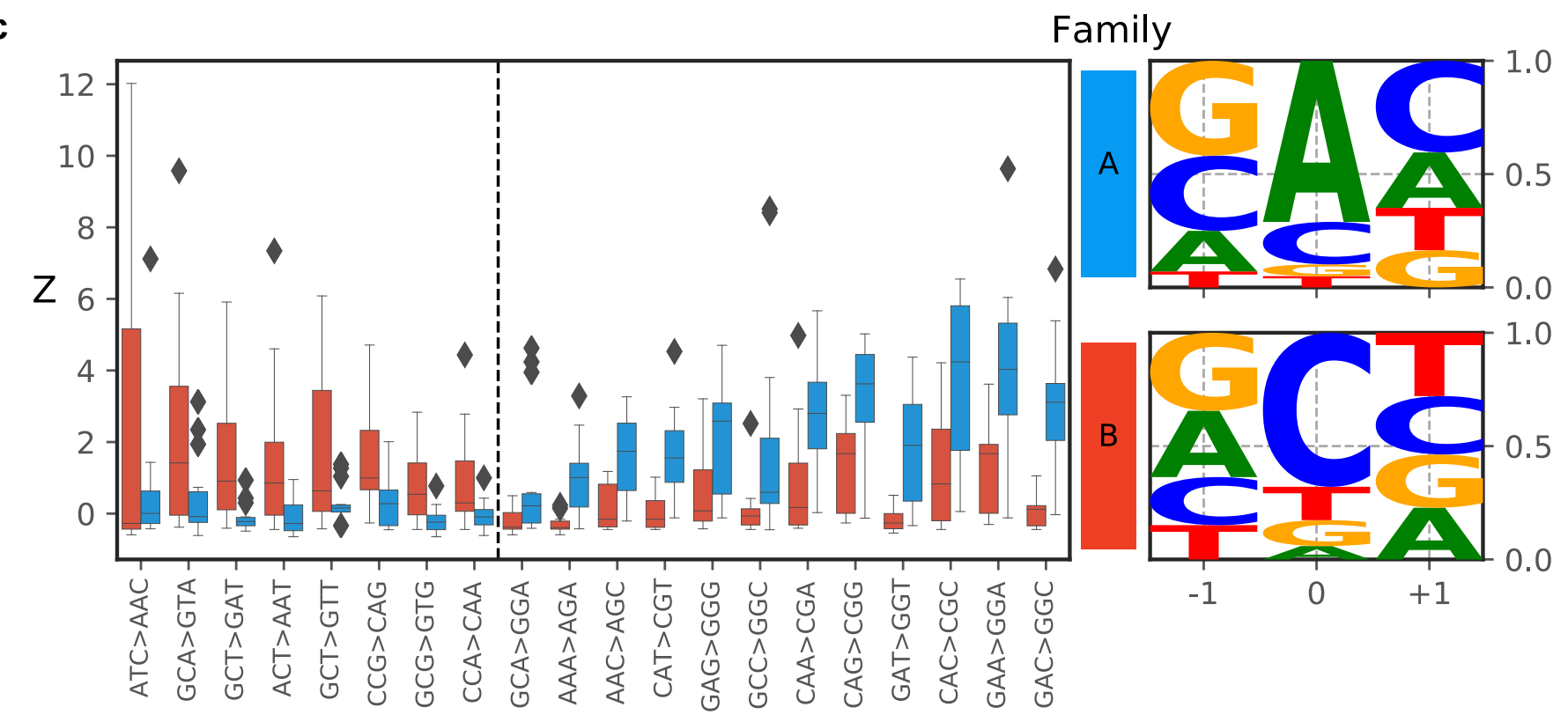




\section{Supplementary Figure 1}

a

$\begin{array}{lllllllll}\mathrm{kDa} & \mathrm{L} & 1 & 2 & 3 & 4 & 5 & 6 & 7\end{array}$

250

150

100

75

50

37

b
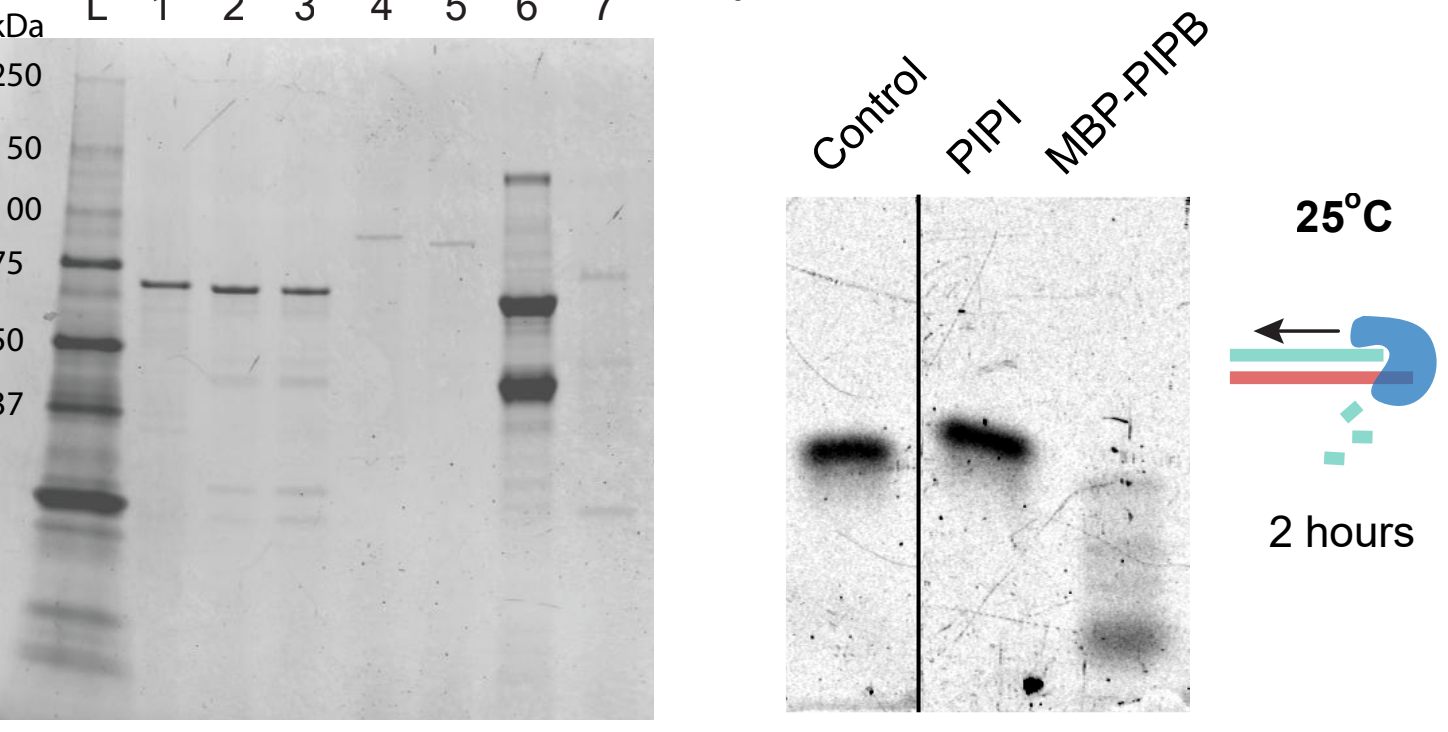
Table 1. Error rates (per base) for thermophilic DNA polymerases.

\begin{tabular}{|c|c|c|c|c|c|}
\hline Origin & Reaction & $\begin{array}{c}\text { Temperature } \\
\left({ }^{\circ} \mathrm{C}\right)\end{array}$ & \begin{tabular}{|c|} 
Substitution rate \\
(base $^{-1}$ )
\end{tabular} & $\begin{array}{l}\text { Deletion rate } \\
\text { (base }{ }^{-1} \text { ) }\end{array}$ & $\begin{array}{c}\text { Insertion rate } \\
\left(\text { base }^{-1}\right)\end{array}$ \\
\hline \multirow{11}{*}{ Thermophile } & $\mathrm{Q}^{\mathrm{NB}}$ & 72 & $4.44 \times 10^{-6}$ & $9.50 \times 10^{-7}$ & $1.37 \times 10^{7}$ \\
\hline & Q5 & 30 & $6.04 \times 10^{-6}$ & $7.45 \times 10^{-7}$ & $5.31 \times 10^{-7}$ \\
\hline & Q5 & 72 & $5.38 \times 10^{-6}$ & $1.56 \times 10^{-7}$ & $5.05 \times 10^{8}$ \\
\hline & Tag & 30 & $6.32 \times 10^{-5}$ & $2.27 \times 10^{-6}$ & $2.01 \times 10^{6}$ \\
\hline & Tag & 50 & $2.18 \times 10^{-4}$ & $2.18 \times 10^{-5}$ & $3.53 \times 10^{6}$ \\
\hline & Phusion ${ }^{N B}$ & 30 & $2.51 \times 10^{-5}$ & $1.82 \times 10^{-8}$ & $8.32 \times 10^{-7}$ \\
\hline & Phusion ${ }^{N B}$ & 50 & $8.11 \times 10^{-6}$ & ND & $1.95 \times 10^{6}$ \\
\hline & Phusion & 72 & $5.05 \times 10^{-6}$ & ND & $9.30 \times 10^{8}$ \\
\hline & Phusion & 30 & $2.02 \times 10^{-5}$ & $2.32 \times 10^{-6}$ & $4.81 \times 10^{-7}$ \\
\hline & Phusion & 50 & $3.64 \times 10^{-5}$ & $2.46 \times 10^{-6}$ & $4.84 \times 10^{-7}$ \\
\hline & Phusion & 72 & $1.24 \times 10^{-5}$ & $3.36 \times 10^{-7}$ & $5.11 \times 10^{-7}$ \\
\hline
\end{tabular}

${ }^{\mathrm{NB}}=$ reaction carried out in native buffer supplied by the manufacturer.

${ }^{\mathrm{ND}}=$ Error frequency below the detectable error baseline. 
Table 2. Error rates (per base) for psychrophilic DNA polymerases,

\begin{tabular}{|c|c|c|c|c|c|}
\hline Origin & Reaction & $\begin{array}{c}\text { Temperature } \\
\text { (e.) }\end{array}$ & $\begin{array}{c}\text { Substitution rate } \\
\text { (base }^{-1} \text { ) }\end{array}$ & $\begin{array}{l}\text { Deletion rate } \\
\quad \text { (base }^{-1} \text { ) }\end{array}$ & $\begin{array}{c}\text { Insertion rate } \\
\quad \text { (base }^{-1} \text { ) }\end{array}$ \\
\hline \multirow{6}{*}{ Psychrophile } & MBP-PIPB & 10 & $9.52 \times 10^{-6}$ & $1.84 \times 10^{6}$ & $1.26 \times 10^{-6}$ \\
\hline & MBP-PIPB & 20 & $2.55 \times 10^{-5}$ & $2.20 \times 10^{-5}$ & $1.09 \times 10^{-6}$ \\
\hline & PIPI & 10 & $3.87 \times 10^{-5}$ & $1.48 \times 10^{6}$ & $1.62 \times 10^{-7}$ \\
\hline & PIPI & 20 & $6.34 \times 10^{-5}$ & $4.15 \times 10^{6}$ & $2.20 \times 10^{-7}$ \\
\hline & PIPI & 37 & $1.83 \times 10^{-4}$ & $1.59 \times 10^{-5}$ & ND \\
\hline & PIPI & 50 & $2.11 \times 10^{-4}$ & $8.47 \times 10^{6}$ & ND \\
\hline
\end{tabular}

$\mathrm{ND}=$ Error frequency below the detectable error baseline. 
Table 3. Error rates (per base) for mesophilic DNA polymerases.

\begin{tabular}{|c|c|c|c|c|c|}
\hline Origin & Reaction & $\begin{array}{c}\text { Temperature } \\
\left({ }^{\circ} \mathrm{C}\right)\end{array}$ & \begin{tabular}{|c} 
Substitution rate \\
(base $^{-1}$ )
\end{tabular} & $\begin{array}{l}\text { Deletion rate } \\
\text { (base }{ }^{-1} \text { ) }\end{array}$ & $\begin{array}{c}\text { Insertion rate } \\
\left.\text { (base }^{-1}\right)\end{array}$ \\
\hline \multirow{11}{*}{ Mesophile } & KleExo- & 10 & $4.20 \times 10^{-5}$ & $7.65 \times 10^{-6}$ & $3.38 \times 10^{-7}$ \\
\hline & KleExo- & 20 & $6.91 \times 10^{-5}$ & $8.55 \times 10^{-6}$ & ND \\
\hline & KleExo- & 37 & $1.07 \times 10^{-3}$ & $1.75 \times 10^{-4}$ & $4.39 \times 10^{7}$ \\
\hline & KleExo- & 50 & $1.38 \times 10^{-3}$ & $1.94 \times 10^{-4}$ & $3.38 \times 10^{6}$ \\
\hline & KleLF & 10 & $8.53 \times 10^{-6}$ & ND & $2.29 \times 10^{8}$ \\
\hline & KleLF & 20 & $1.56 \times 10^{-5}$ & $1.12 \times 10^{-7}$ & $2.14 \times 10^{-7}$ \\
\hline & KleLF & 37 & $2.99 \times 10^{-5}$ & $1.20 \times 10^{-7}$ & $1.43 \times 10^{-7}$ \\
\hline & KleLF & 50 & $2.00 \times 10^{-5}$ & ND & $5.45 \times 10^{8}$ \\
\hline & T4 & 10 & $3.25 \times 10^{-5}$ & $1.32 \times 10^{-6}$ & $2.37 \times 10^{8}$ \\
\hline & $\mathrm{T} 4$ & 37 & $5.92 \times 10^{-5}$ & $1.17 \times 10^{-6}$ & ND \\
\hline & T4 & 50 & $1.45 \times 10^{-5}$ & ND & ND \\
\hline
\end{tabular}

${ }^{\mathrm{ND}}=$ Error frequency below the detectable error baseline. 